Acta Neuropsychiatrica

cambridge.org/neu

\section{Review Article}

Cite this article: Galyuk TM and Loonen AJM. (2021) Putative role of vitamin D in the mechanism of alcoholism and other addictions - a hypothesis. Acta Neuropsychiatrica 33:1-8. doi: $10.1017 /$ neu.2020.41

Received: 28 August 2020 Revised: 29 October 2020

Accepted: 30 October 2020

First published online: 13 November 2020

\section{Key Words:}

addiction; calcidiol; calcitriol; vitamin D

Receptor; dopaminergic neurotransmission

Author for correspondence:

Anton J.M. Loonen, Email: a.j.m.loonen@rug.nl

\title{
Putative role of vitamin $D$ in the mechanism of alcoholism and other addictions - a hypothesis
}

\section{Tanya M. Galyuk ${ }^{1}$ and Anton J.M. Loonen ${ }^{2}$ (1)}

${ }^{1}$ de Hoop Geestelijke GezondheidsZorg (GGZ), Ambulatory Addiction Care, Dordrecht, Netherlands and ${ }^{2}$ Unit of PharmacoTherapy, -Epidemiology and -Economics, Groningen Research Institute of Pharmacy, University of Groningen, Groningen, Netherlands (c) Scandinavian College of Neuropsychopharmacology 2020. This is an Open Access article, distributed under the terms of the Creative Commons Attribution licence (http://creativecommons.org/licenses/ by/4.0/), which permits unrestricted re-use, distribution, and reproduction in any medium, provided the original work is properly cited.

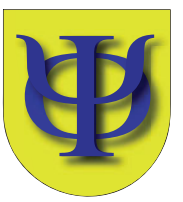

\begin{abstract}
Objective: Vitamin D deficiency may be a clinical problem in patients with addictions. The authors systematically searched for studies addressing vitamin D and addiction and develop a hypothesis which can direct future research of the possible mechanistic role of vitamin D in the process of addiction. Methods: Systematic review of the literature found in PubMed and EMBASE followed by narrative review combined with clinical experiences leading to hypotheses for future research. Results: Only five articles were identified about a role of vitamin $\mathrm{D}$ in the pathophysiology of addiction. Their results are in line with a possible influence of vitamin D in dopaminergic transmission. The cerebral vitamin D status depends on the functionality of genetic variants of vitamin $\mathrm{D}$ receptor and other involved genes. Routine serum calcidiol levels may not adequately reflect cerebral vitamin D status. Uncertainty exists regarding appropriate calcidiol blood levels and proper dosages for affecting the central nervous system (CNS). Conclusions: The putative pathophysiological role of vitamin $\mathrm{D}$ in substance abuse has been insufficiently studied which calls to more studies how to measure cerebral vitamin D status in clinical practice. Research is indicated whether vitamin D supplementation should use higher dosages and aim to reach higher calcidiol serum levels. Measuring dopaminergic functioning within the prefrontal cortex as reflected by neuropsychological tests selected as suitable could be a appropriate proxy for the cerebral vitamin D status when studying the pharmacogenomics of this functionality in patients.
\end{abstract}

\section{Summations}

- Cerebral vitamin D status may diverge from serum calcidiol levels

- Cerebral vitamin D status may depend on pharmacogenetic characteristics

- Treatment of CNS diseases with vitamin D may be indicated in only specific patient characteristics

\section{Considerations}

- Only five papers of vitamin D and addiction were discovered searching PubMed and EMBASE

- The impact of relevant pharmacogenotypes on CNS effects of calcitriol has hardly been studied

- A well-designed trial of the efficacy of cholecalciferol in preventing depression had negative results

\section{Introduction}

Vitamin D belongs to a group of fat-soluble prohormones of the chemical subclass of steroids which include retinoic acid, sex hormones and adrenal steroids. Two clinically relevant forms of vitamin $D$ exist, namely cholecalciferol $\left(D_{3}\right)$ and ergocalciferol $\left(D_{2}\right)$. Vitamin $D_{2}$ is obtained from food, while the level of vitamin $D_{3}$ depends on its synthesis from 7-dehydrocholesterol (a cholesterol derivative) within the skin under the influence of ultraviolet radiation (Webb et al., 1988). In the liver, vitamin $\mathrm{D}_{3}$ is converted into the intermediate calcidiol (25-(OH)-D3) through hydroxylation by means of 25-hydroxylase. Calcidiol is, in turn, converted within the kidneys by $25 \mathrm{OHD}-1-\alpha$-hydroxylase (CYP27B1) into an active metabolite calcitriol $\left(1,25-(\mathrm{OH})_{2}-\mathrm{D}_{3}\right)$ (Fig. 1). Calcitriol is 


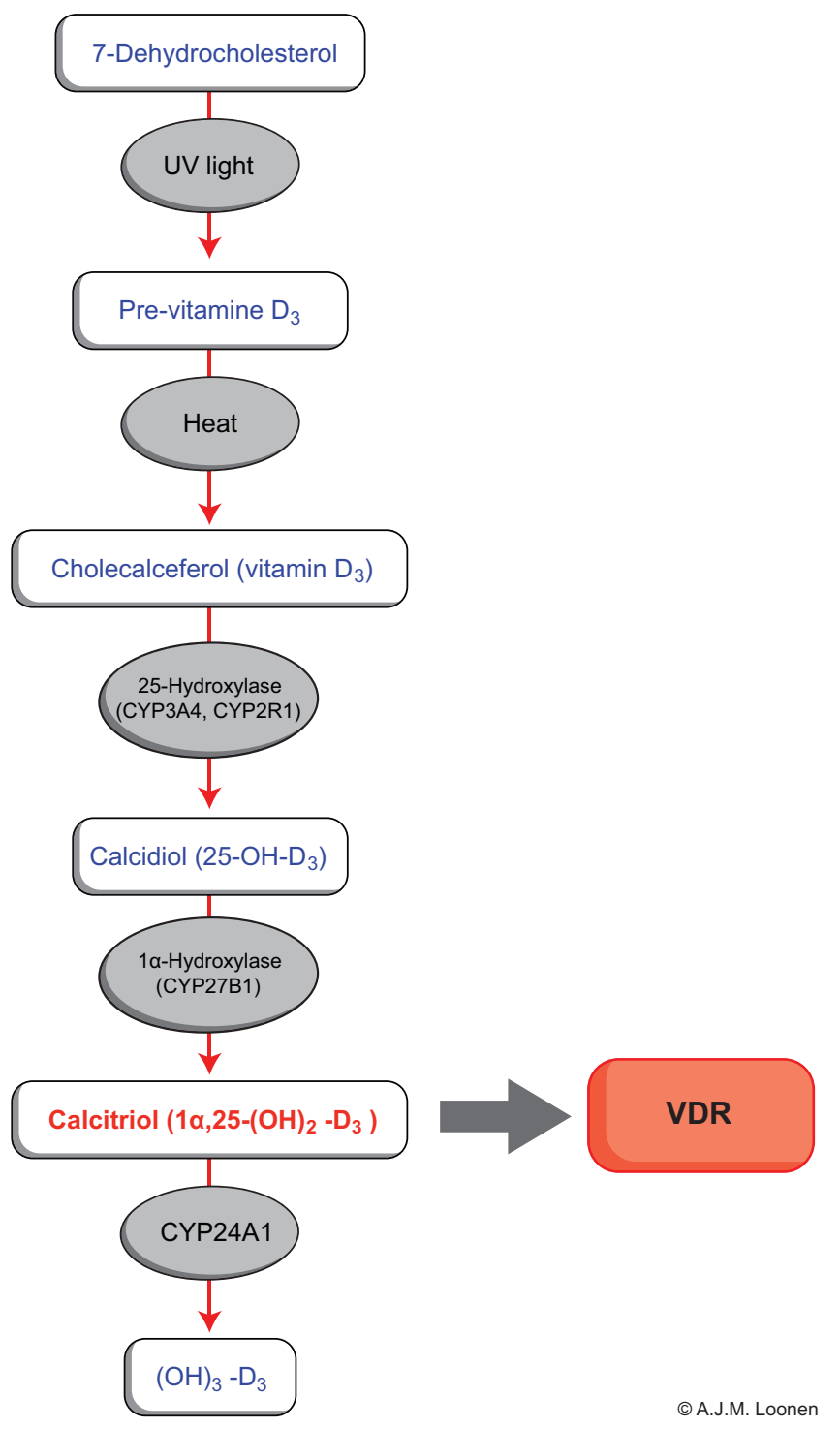

Fig. 1. Simplified pathway for vitamin D biosynthesis and inactivation (Prosser and Jones, 2004). Cholecalciferol is synthetised within the skin. Calcitriol is the biologically active neurohormone which reacts with vitamin D receptor (VDR).

structurally related to the steroid hormones and it is not classified as a vitamin, but as a prohormone (Hollick, 2002).

Metabolite calcidiol is the most important circulating form of vitamin $\mathrm{D}$, but it has a low biological activity. In order to determine the value of vitamin $\mathrm{D}$, it is considered sufficient to measure the calcidiol level in serum. It is, however, known that the active metabolite calcitriol has far higher affinity to the vitamin D receptor (VDR). VDR is involved in the regulation of more than 900 genes and a range of physiological processes (Kongsbak et al., 2013). VDR is present in cytoplasm and can be retrieved in vascular endothelial cells and the brain; pancreas; skin; cartilage; adrenals; mammary gland; muscle; liver, thyroid and immune cells (Pike and Meyer, 2010).

There are currently many hundreds of allelic variants of the VDR gene locus described and numerous studies have investigated the association of such variants (e.g. BsmI, FokI, TagI and ApaI) with the effect of vitamin D (Mukhtar et al., 2019). VDR gene polymorphisms can lead to a malfunction of calcitriol. In this way, it may limit vitamin $\mathrm{D}$ having an anti-inflammatory function by altering the calcitriol binding sites (Cieslinska et al., 2018). VDR has also been found to upregulate the expression of the MDR1 gene encoding P-glycoprotein as well as that of CYP3A4 and, to a lesser extent, CYP2B6 and CYP2C9 genes (Drocourt et al., 2002; Chow et al., 2011).

As vitamin $\mathrm{D}$ deficiency and vitamin $\mathrm{D}$ receptor (VDR) gene polymorphisms have been linked to a wide range of diseases (e.g. inflammation, including various autoimmune diseases) (Altieri et al., 2017; Martens et al., 2020), a causal relationship between various syndromes and the deactivation of VDR should obviously be considered. Deactivation of VDR is, however, far from the only mechanism how the effects of calcitriol can be affected. This can also be related to affecting calcitriol's metabolism and transportation to sites of action.

A recent model for the mechanism of a set of essential mental symptoms defines two parallel circuits within the forebrain regulating the intensity of reward-seeking or distress-avoiding behaviour (Loonen and Ivanova, 2016, 2018; Loonen et al, 2016). These circuits include the core and shell part of the nucleus accumbens, respectively. When the reward-seeking behaviour is successful, the individual experiences pleasure (hedonia) and when distress-avoiding behaviour is successful, feelings of happiness (euphoria) occur. The motivation to express these two types of behaviour depends on the activity of ascending monoaminergic neurons originating within the midbrain, more specifically the ventral tegmental area (dopamine, DA), the upper raphe nuclei (5-hydroxytryptamine, $5-\mathrm{HT}$ ) and the locus coeruleus (norepinephrine, NE). These ascending pathways are controlled by terminals originating within the habenuloid complex (Batalla et al., 2017). Dopaminergic neurons running to the core of the nucleus accumbens in particular are essential for substance use disorders but also have an important role in regulating psychomotor activity in depression, psychosis and mania. Dopaminergic neurons also run to the dorsal striatum and frontal and temporal lobes and are involved in a variety of neuropsychiatric symptoms concerning kinesis (Parkinson's disease, Tourette syndrome); obsessions and compulsions (obsessive compulsive disorder); vigilance (attention deficiency hyperactivity disorder (ADHD)); anxiety; memory; hallucinations and delusions. The enzyme catechol-O-methyltransferase (COMT) metabolises DA and the COMT Val158Met single-nucleotide polymorphism (rs4680) significantly affects DA efficacy and tone within the prefrontal cortex (PFC), which moderates the effects of dopaminergic drugs on PFC-dependent cognitive functions (e.g., working memory, selective attention and executive function) (Schacht, 2016).

The aim of this study was originally to investigate whether vitamin $\mathrm{D}$ deficiency and/or VDR is pathophysiologically involved in the process of addiction and to review the clinical evidence justifying treatment of alcoholism and other forms of addiction with vitamin D. We hypothesised that the vitamin D status affects cerebral dopaminergic neurotransmission according to the schedule represented in Fig. 2. Unfortunately, this subject turned out to have hardly been investigated until now. We describe important considerations for the design of future research.

\section{Systematic review}

\section{Identification}

During a systematic search in December 2019 of the PubMed database of the National Library of Medicine as well as the EMBASE database published by Elsevier, we used the following keywords and syntaxis: 


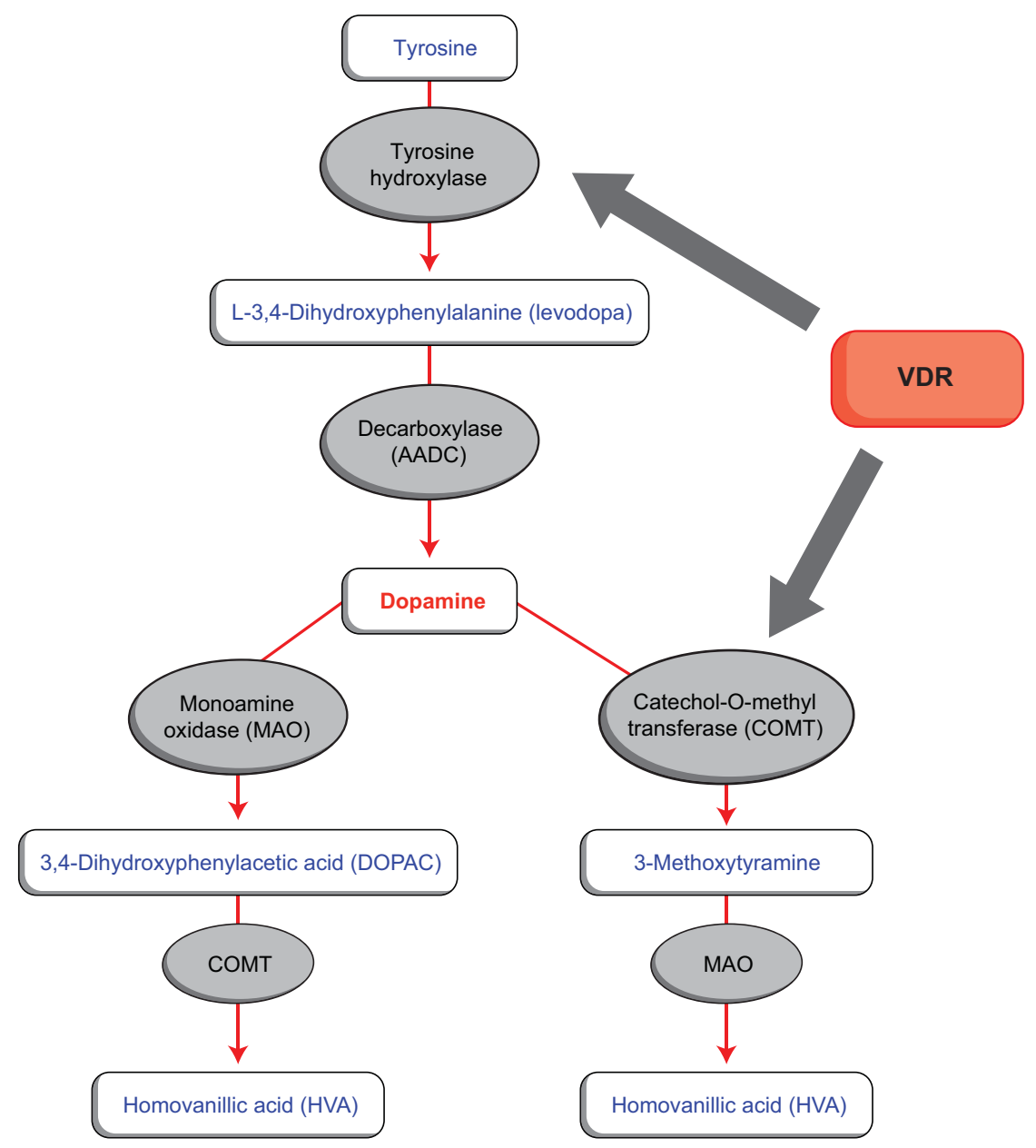

Fig. 2. Possible influence of vitamin $D$ on biosynthesis and inactivation of dopamine (Sibley et al., 2018). AADC, aromatic L-amino acid decarboxylase; VDR, vitamin D (c) A.J.M. Loonen receptor.

(vitamin d AND dopamine) OR (VDR AND dopamine) OR (VDR AND addiction) OR (vitamin $\mathrm{d}$ AND addiction) OR (vitamin $\mathrm{d}$ AND alcohol) OR (vitamin d AND stimulants) OR (VDR AND alcohol) OR (VDR AND stimulants) OR (vitamin d AND cocaine) OR (VDR AND cocaine)

Using this search strategy, we found 2293 titles in PubMed and 4151 titles in EMBASE. The number of review articles was 429 in PubMed and 1306 in EMBASE; the number of systematic reviews was 48 in PubMed and 25 in EMBASE. The number of randomised controlled trials was 67 in PubMed and 59 in EMBASE. Combining the search with genetic polymorphism gave 60 titles in PubMed and 78 titles in EMBASE.

By combining these searches, after considering the titles and selecting articles dealing with the central nervous system (CNS), neurological and/or mental disorders (more specifically addictive disorders) and after removing duplicates, we obtained a set of 178 studies, where two studies were listed twice, so ultimately in total 176 studies (Supplementary Table 1). After screening the summaries, some content duplicates and all irrelevant studies were removed (Table 1). As a result, we identified only five studies which specifically addressed the subject: one narrative review of animal data (Eserian, 2013); one systematic review (Tardelli et al., 2017); one cross-sectional genetic association study (Wrzosek et al., 2014) and two relevant clinical studies (Ghaderi et al., 2017, 2020) regarding the relationship of vitamin $\mathrm{D}$ with addiction (Table 2). Nevertheless, these studies were considered to be of interest for theory formation as is discussed below. In addition, we found
22 clinical studies on the influence of vitamin D in psychiatric disorders, including a comprehensive systematic review of the relationship between vitamin D and psychotic disorders (Adamson et al., 2017).

\section{Description}

In her narrative review of animal studies, Eserian (2013) obtained support for the hypothesis that vitamin $\mathrm{D}$ would be an effective treatment approach for drug abuse and addiction. An important point may be that the administration of a single dose of vitamin $\mathrm{D}$ to new-born female rats resulted in augmentation of DA or its major metabolite in the brainstem, the hypothalamus and the striatum in adulthood (Tekes et al., 2009a), indicating increased dopaminergic activity. The alterations were partly maintained transgenerationally in their (untreated) adult female offspring (Tekes et al., 2009b). Prenatal vitamin D deficiency delays or decreases the expression of genetic factors in rat embryos which are critical for the orderly development of DA neurons (Cui et al., 2010). This probably corresponds to the decreased neonatal expression of catechol-O-methyltransferase (COMT) gene of these 'developmental vitamin D (DVD)-deficient' rats (Kesby et al., 2010). After reaching adulthood, (especially female) DVDdeficient rats show an increased sensitivity to the behavioural effects of amphetamine as well as an increased expression of the dopamine transporter (DAT) protein, which is one of the targets of this drug. These findings clearly show that vitamin D deficiency 
Table 1. Number of studies covering the effects of vitamin D in combination with neurological and psychiatric illnesses and/or addiction

\begin{tabular}{|c|c|}
\hline Vitamin D and diagnosis & $\begin{array}{l}\text { Number of } \\
\text { found articles }\end{array}$ \\
\hline Vitamin D and addiction & 5 \\
\hline \multicolumn{2}{|l|}{$\begin{array}{l}\text { Addiction (for complete overview, please refer to } \\
\text { Table 2). }\end{array}$} \\
\hline \multicolumn{2}{|l|}{ Vitamin D and neurology diseases } \\
\hline Parkinson's disease & 10 \\
\hline Alzheimer's disease & 3 \\
\hline Other neurological diseases & 8 \\
\hline RLS (restless legs syndrome) & 1 \\
\hline \multicolumn{2}{|l|}{ Vitamin D and psychiatric illnesses } \\
\hline Psychosis & 2 \\
\hline Autism & 1 \\
\hline Obsessive compulsive disorder & 1 \\
\hline Attention deficiency hyperactivity disorder & 5 \\
\hline Depression & 2 \\
\hline Schizophrenia and bipolarity & 8 \\
\hline $\begin{array}{l}\text { Neurodevelopmental diseases with ADHD, autism } \\
\text { and schizophrenia }\end{array}$ & 1 \\
\hline \multicolumn{2}{|l|}{ Others } \\
\hline Vitamin D and brain development & 4 \\
\hline Publications pre-2010 about vitamin D and alcohol & 7 \\
\hline Non-relevant articles & 118 \\
\hline Total number & 176 \\
\hline
\end{tabular}

has a long-lasting influence on the functioning of dopaminergic neurotransmission. The mechanism of these alterations are not yet known, but apart from being a potent inducer of endogenous glial cell line-derived neurotrophic factor (GDNF), calcitriol has also been found to increase the expression of tyrosine hydroxylase (TH) in vitro (Puchacz et al., 1996). GDNF has a role in survival of adult dopaminergic neurons and in negatively regulating the actions of drugs of abuse (Carnicella and Ron, 2009). Moreover, calcitriol has been reported to protect dopaminergic neurons against neurotoxicity by oxidative stress (Ibi et al., 2001). In addition, vitamin $\mathrm{D}$ can increase glutathione levels and inhibit the expression of inducible nitric oxide synthase (iNOS) (Garcion et al., 1998, 1999), which both may result in strong antioxidant protection of dopaminergic neurons. It has been reported that vitamin $\mathrm{D}$ protects dopaminergic (and serotonergic) neurons against depletion by neurotoxic dosages of methamphetamine (Cass et al., 2006). This neurotoxicity is associated with an increased expression of neuronal nitric oxide synthase (nNOS). It can be concluded that the pleiotropic effects of vitamin D observed in animal studies suggest its involvement of the functioning of dopaminergic neurotransmission.

Tardelli et al. (2017) systematically searched the literature in order to evaluate the association between ordinary alcohol use and vitamin D serum levels. Although, they identified 49 mainly cross-sectional $(71.4 \%)$ studies of extensively varying size (from 10 to 14641 ), they could not extract sufficient quantitative data to meta-analyse them. In almost all studies with a large patient number $(>1000)$, a positive association (or no association) was found between regular alcohol use and vitamin D levels. These types of study are, however, not very helpful within the context of the present article, because the relationship may importantly differ in patients with alcohol use disorder from social drinkers: apart from a possible relationship with reward-seeking appetitive behaviour, this could also be related to liver damage or low exposure to sunlight.

Wrzosek and colleagues (2014) studied a possible association of FokI (rs2228570, T/C) single-nucleotide polymorphism of VDR gene, which is known to affect the VDR function. They included 148 patients (106 males and 42 females) with alcohol dependence according to DSM-IV criteria and 212 healthy controls. Their study may be statistically underpowered concerning the genetic difference between patients and controls, but they also measured impulsivity by applying the Barratt Impulsiveness Scale (BIS-11). In male patients, but not in females, (attentional) impulsivity according to BIS-11 scores was affected by their FokI VDR genotype. This might be related to an inability to drink alcohol in a controlled manner.

Ghaderi et al. $(2017,2020)$ published the results of two randomised controlled trials of $50000 \mathrm{IU}$ of vitamin D or matching placebo taken every 2 weeks for 12 and 24 weeks, respectively. The level of blindness was not specified. They included only men, all of whom were receiving methadone maintenance treatment. They corrected for age and body mass index (BMI) by post-, respectively, pre-stratification. In their first study of 68 patients $($ verum $=34$, placebo $=34)$, they concentrated on metabolic parameters, but as a primary outcome measured sleep quality and symptoms of depression and anxiety by administering specific questionnaires. Vitamin D significantly improved sleep quality and depressive symptoms, but anxiety scores did not alter (or only after post-stratification). Similar results concerning depression and anxiety scores were obtained in the second study of 64 different patients $($ verum $=32$, placebo $=32$ ). In this second study, the authors also measured cognitive function by administering a series of neuropsychological tests and found several significant differences between verum and placebo-treated patients.

\section{Interpretation}

The foregoing can be interpreted as that - although the evidence is weak - VDR might play a role in the pathophysiology of addiction. An essential aspect of addiction is the chance of relapse to abusing a specific substance when exposure occurs again after a period of abstinence. Additionally, at an earlier stage, specific sensory information (cues) lead to increased motivation to obtain alcohol or drugs. Both essential components of the 'addiction process' are directly linked to a hijacking and augmenting of the activity of reward-seeking forebrain circuits which include the core of the nucleus accumbens (Loonen and Ivanova, 2016, 2018; Loonen et al., 2016). The addiction process is believed to exist from a three-stage cycle: binge/intoxication, withdrawal/negative affect and preoccupation/anticipation (Koob and Volkow, 2010). The second component of this cycle is probably related to a parallel activation of the distress-avoiding circuit, including the shell of the nucleus accumbens. The activity of these two circuits is regulated by the lateral and medial habenula, respectively, which affect the activity of ascending monoaminergic (DA, 5-HT and NE) pathways from the midbrain (Batalla et al., 2017). DA most extensively facilitates reward-seeking behaviour, and dopaminergic inactivity resulting from intoxication with DA-depleting 
Table 2. Studies of the effects of vitamin D in addiction

\begin{tabular}{|c|c|c|c|}
\hline Studied issue & Country & Type of study & Measurement results \\
\hline $\begin{array}{l}\text { Vitamin D as an effective treatment approach for } \\
\text { drug abuse and addiction (Eserian, 2013) }\end{array}$ & $\begin{array}{l}\text { Brazil, } \\
2013\end{array}$ & $\begin{array}{l}\text { Narrative } \\
\text { review }\end{array}$ & $\begin{array}{l}\text { The effects of vitamin D on the central nervous system support this } \\
\text { hypothesis, which can provide a new direction towards an effective } \\
\text { treatment approach for drug abuse and addiction. }\end{array}$ \\
\hline $\begin{array}{l}\text { Vitamin D and alcohol: a review of the current litera- } \\
\text { ture (Tardelli et al., 2017) }\end{array}$ & $\begin{array}{l}\text { Brazil, } \\
2016\end{array}$ & $\begin{array}{l}\text { Systematic } \\
\text { review }\end{array}$ & $\begin{array}{l}\text { Controversial results. Additional research with standardised method- } \\
\text { ology is necessary to demonstrate the real impact of alcohol con- } \\
\text { sumption on vitamin D serum levels. }\end{array}$ \\
\hline $\begin{array}{l}\text { Association between Fok VDR polymorphism and } \\
\text { impulsivity by alcohol-dependent patients (Wrzosek } \\
\text { et al., 2014) }\end{array}$ & $\begin{array}{l}\text { Poland, } \\
2014\end{array}$ & $\begin{array}{l}\text { Cross-sec- } \\
\text { tional associa- } \\
\text { tion study }\end{array}$ & $\begin{array}{l}\text { Study demonstrates an association between a polymorphism of VDR } \\
\text { and impulsivity in alcohol dependence. }\end{array}$ \\
\hline $\begin{array}{l}\text { Clinical trial of the effects of vitamin D supplemen- } \\
\text { tation on psychological symptoms and metabolic } \\
\text { profiles in maintenance methadone treatment } \\
\text { patients (Ghaderi et al., 2017) }\end{array}$ & $\begin{array}{l}\text { Iran, } \\
2017\end{array}$ & Clinical trial & $\begin{array}{l}\text { Clinical trial of } 50000 \mathrm{IU} \text { vitamin D every } 2 \text { weeks for } 12 \text { weeks on } \\
\text { sleep and depression scores and metabolic parameters in } 68 \text { patients } \\
\text { on methadone therapy. Study shows favourable effects. }\end{array}$ \\
\hline $\begin{array}{l}\text { Exploring the effects of vitamin D supplementation } \\
\text { on cognitive functions and mental health status in } \\
\text { subjects under methadone maintenance treatment } \\
\text { (Ghaderi et al., 2020) }\end{array}$ & $\begin{array}{l}\text { Iran, } \\
2019\end{array}$ & Clinical trial & $\begin{array}{l}\text { Clinical trial of } 50000 \mathrm{IU} \text { vitamin D every } 2 \text { weeks for } 24 \text { weeks on } \\
\text { cognitive defects in } 64 \text { patients on methadone therapy. Significant } \\
\text { differences were demonstrated by applying neuropsychological tests. }\end{array}$ \\
\hline
\end{tabular}

substances results in relative overactivity of the distress-avoiding circuit leading to feelings of misery. This mechanism puts the protective activity of calcitriol against the neurotoxic effects of DAdepleting drugs in a more specific context (Cass et al., 2006). Further, the association of a functional polymorphism of the $V D R$ gene and impulsivity can be linked with the activity of ascending dopaminergic pathways to the (previously described) reward-seeking circuitry.

The biochemical mechanism which lies behind these activities is unclear. It has been suggested that vitamin D modulates GDNF, which has neuroprotective activity on dopaminergic neurons (Eserian, 2013), but vitamin D also has many other effects. Another neuronal mechanism might be that vitamin D regulates the activity of glutamatergic neurons projecting to the lateral habenula which inhibit the activity of ascending dopaminergic neurons. In addition, calcitriol could regulate the processing of DA, for example, by affecting the expression/or activity of DA transporters (DAT, vesicular monoamine transporter); enzymes (TH, monoamine oxidase, COMT) and/or DA receptors.

The role of vitamin D on the functioning of COMT in particular may be of interest within the context of this article. New-born DVD-deficient rats show decreased expression of COMT gene (Kesby et al., 2010). In an in vitro model, stimulation of overexpressed VDR resulted in elevated COMT gene expression (Pertile et al., 2016). The activity of COMT may have an important influence on the functioning of the prefrontal cerebral cortex, which probably explains the association of the functional COMT Val158Met polymorphism with certain neuropsychiatric disorders such as ADHD (Taylor, 2018). This justifies a hypothesis which proposes that the functioning of the PFC may adequately reflect cerebral vitamin D status. The results of Wrzosek et al. (2014) and those of Ghaderi et al. $(2017,2020)$ possibly also correspond to an effect within the prefrontal cerebral cortex.

A complication may be induced, both in studies and in daily practice, by the fact that patients are usually supplemented with cholecalciferol (vitamin D3), while the actual neurohormone is calcitriol $\left(1,25-(\mathrm{OH})_{2}-\mathrm{D} 3\right)$. Measuring total calcidiol (25-OH-D3) levels in serum is, up to now, considered to be a good indicator of vitamin $\mathrm{D}$ status. However, the described genetic variability decreases the reliability of this measure. In addition, polymorphisms of vitamin D binding protein (VDBP) gene may determine the free concentration and therefore penetration into the brain (Newton et al., 2019), while the ratio between calcidiol and calcitriol may depend on genetic variants of enzymes which synthesise and metabolise calcitriol forms, respectively, CYP27B1 and CYP24A1. The role of vitamin D can only be made clear when we consider the influence of this genetic variability and for interpreting the result of treatment we need to correct the serum calcidiol level in order to obtain a better measure for the vitamin D status of the patient. Our hypothesis about the suspected effect of $V D R$ follows the logical order as shown in Fig. 2.

\section{Cases}

In spite of the many uncertainties, we obtained some positive results in our clinical practice with the addition of vitamin $\mathrm{D}$ in the treatment of addicted patients. We started in one of them, a 49-yearold single male with a serious cocaine use disorder and moderate alcohol use disorder. (patient A), vitamin D supplementation with oral $25000 \mathrm{IU}$ cholecalciferol/1 ml ampoules; initially, $25000 \mathrm{IU}$ once weekly during 8 weeks and later switched to a dosage of $25000 \mathrm{IU}$ once per 2 weeks. In total, he received 15 ampoules. One month after starting supplementation with ampoules, he also took $800 \mathrm{IU}$ cholecalciferol tablets daily, along with nalmefene against craving for alcohol, vitamin B complex twice daily and thiamine $50 \mathrm{mg}$ twice daily. After a few months, his serum calcidiol had increased to $108 \mathrm{nmol} / \mathrm{l}$ (Table 3) and the patient felt considerably better; all depressive complaints had disappeared without a specific antidepressant drug treatment being taken. Another patient, a 40-year-old woman (patient $\mathrm{D}$ ), sought help due to a severe tobacco use disorder with underlying unspecified ADHD/ADD problems. When admitted, she used $10 \mathrm{mg}$ of methylphenidate up to 3-4 times daily and once daily $20 \mathrm{mg}$ of citalopram in addition to nicotine patches for quitting smoking. Laboratory examination revealed a serum calcidiol level of $15 \mathrm{nmol} / \mathrm{l}$ and no other deviations. Based on these results, she was treated with oral dosage of $50000 \mathrm{IU}$ (as $1 \mathrm{ml}=25000 \mathrm{IU}$ ampoules) once weekly for 8 weeks. After 8 weeks, her calcidiol had increased to $70 \mathrm{nmol} / \mathrm{l}$. In the meantime, she had stopped using methylphenidate and had started a tapering down schedule to stop citalopram. 
Table 3. Levels of vitamin D in four of our patients

\begin{tabular}{lcc}
\hline Patient & Initial level of Vitamin D & Vitamin D after treatment \\
\hline A & $15 \mathrm{nmol} / \mathrm{l}$ & $108 \mathrm{nmol} / \mathrm{l}$ \\
\hline B & $26 \mathrm{nmol} / \mathrm{l}$ & $49 \mathrm{nmol} / \mathrm{l}$ \\
\hline C & $33 \mathrm{nmol} / \mathrm{l}$ & $48 \mathrm{nmol} / \mathrm{l}$ \\
\hline D & $15 \mathrm{nmol} / \mathrm{l}$ & $70 \mathrm{nmol} / \mathrm{l}$ \\
\hline
\end{tabular}

\section{Discussion}

In both severely addicted patients, substantial mood problems responded quickly and well to treatment with relatively high dosages of cholecalciferol. Two other patients (B and C from Table 3) were treated with an oral dose of 1600 IE cholecalciferol (tablets) daily, but this treatment did not result in sufficiently high calcidiol levels (> $75 \mathrm{nmol} / \mathrm{l})$ (Table 3 ). Apart from this dosage consideration, we expect that the response of every addicted patient may depend on the individual VDR polymorphisms in combination with polymorphisms in a variety of still to be determined other genes. As calcidiol has low activity and calcitriol is the true neurohormone, functional variants of CYP27B1 and CYP24A1 could also be relevant for treatment response (Olmoz-Ortiz et al., 2015). Different countries adhere to varying calcidiol levels for defining vitamin D deficiency. A recent meta-analysis of 32 studies resulted in an appropriate lower limit of $30 \mathrm{ng} / \mathrm{ml}(75 \mathrm{nmol} / \mathrm{l})$ (Garland et al, 2014). For the time being this lower limit should be applied in our opinion, but the results of future pharmacogenetic studies could well make individualisation of the treatment goals feasible and advisable.

\section{Required dosage in addiction}

Various dosages of cholecalciferol are recommended for the treatment of different conditions (Pludowski et al., 2018). A regular daily vitamin D supplementation dosage of 3000-5000 IU is advised in general for the majority of disease-specific recommendations (Ekwaru et al., 2014). However, this may be too low in certain CNS diseases. The negative results of a large placebocontrolled clinical trial on the prophylactic activity of daily 2000 IU cholecalciferol on depression or depressive symptoms are probably partly related to the relatively low dosage (Okereke et al., 2020). Uncontrolled treatment with high dosages is on the other hand not desirable. In alternative medical (orthomolecular) practice, extremely high dosages (daily $1000 \mathrm{IU} / \mathrm{kg}$ body weight) are sometimes given (Tutor, 2019); these need all sorts of precautions to prevent adverse effects.

Usage of a biomarker for the cerebral vitamin D status might be a useful addition to this type of studies, especially when trying to find specific reasons for general treatment failure or for identifying factors contributing to specific secondary treatment effects (Ekwaru et al., 2014).

\section{Individualising the dosage}

Correction for body weight (BMI) was encouraged by Ekwaru et al. (2014) who recommend vitamin D supplementation be 2 to 3 times higher for obese subjects and 1.5 times higher for overweight subjects relative to normal-weight subjects. In our opinion, it is more rational to consider BMI in combination with relevant gene polymorphisms which cannot be corrected for by measuring serum calcidiol levels.
Another possibility would be to measure the active form of vitamin $\mathrm{D}$, calcitriol $\left(1,25-(\mathrm{OH})_{2}-\mathrm{D} 3\right)$, directly, but calcitriol serum levels may not adequately reflect vitamin $\mathrm{D}$ reserves due to its relative short and varying half-life and its dependence upon the activity of parathyroid hormone (Souberbielle et al., 2015). Nevertheless, some authors from North America and Brazil advise the measurement of both calcitriol and calcidiol, because in the case of inflammation the serum calcitriol levels can be much higher than that of calcidiol (Blaney et al., 2009). Calcitriol indeed plays an important role in the inflammatory process, but native $\mathrm{TH}$ is also present in some tissues in the body to form the active form of calcitriol without increasing its concentration in the general blood stream (Shah et al., 2006). Moreover, the calcitriol brain/serum ratio is possibly variable, which would limit the value of measuring calcitriol serum levels in diseases of the CNS including addiction.

Many environmental circumstances may affect the vitamin D status of patients with alcohol and/or substance use disorders as well. Heavy smoking is an often-encountered complication in this patient group. Tobacco smoking has a significant effect on calcium and vitamin D metabolism (Brot et al., 1999), which may be partly related to its potency to induce CYP enzymes. In addition, excessive coffee intake (which is common in psychiatric patients in general as well) may be relevant because caffeine inhibits $V D R$ expression and calcitriol-related effect in human osteoblasts in vitro (Rapuri et al., 2007). Apart from the mentioned genetic variables, therefore, these and many other factors may affect the vitamin D status of patients with alcohol and/or substance use disorder.

\section{Conclusion}

From the foregoing, we can conclude that although measuring serum calcidiol levels should be recommended in patients with an alcohol/substance use disorder, serum calcidiol levels may not represent the actual cerebral vitamin D status. This may especially be true in patients with a polymorphism of $V D R$ or other contributing genes such as COMT, VDBP, CYP27B1 and CYP24A1. For the time being treatment of patients with seriously lowered calcidiol levels with a high-dosage regimen of cholecalciferol (ampoules) aiming at calcidiol serum levels above $75 \mathrm{nmol} / \mathrm{l}$ is, at least, often indicated. However, experimental studies addressing the relationship between serum calcidiol levels and cerebral vitamin D status deserve high priority and may be relevant for several CNS disorders. Animal studies would best precede clinical pharmacological experimentation so as to obtain suitable clues for potential contributing factors. In order to determine which supplementary dosages of cholecalciferol is adequate in patients with addiction, a clinical parameter reflecting the cerebral vitamin $\mathrm{D}$ status should be included. Measuring the activity of the frontal cerebral cortex by means of a neuropsychological test battery reflecting COMT activity might be suitable to assess the cerebral vitamin D status in this type of pharmacogenetic research (cf. Ehlis et al., 2007; Ghaderi et al., 2020). Once the relationship with serum calcidiol levels and relevant genotypes is established, corrected calcidiol levels could be applied for therapeutic monitoring.

Supplementary material. To view supplementary material for this article, please visit https://doi.org/10.1017/neu.2020.41

Acknowledgements. The authors greatly appreciate the help of Mrs. Kate Barker (BA, PGCE) who has proofread the manuscript. The authors thank Prof. Dr. Frits A.J. Muskiet (University Medical Centre Groningen (UMCG), University of Groningen, the Netherlands), Dr. Jos Wielders (Meander Medisch Centrum, Amersfoort, the Netherlands), Dr. Glen J.H. Dumont 
(Amsterdam University Medical Center, the Netherlands) for contributing to the process of writing this article.

Conflict of interests. The authors report no conflicts of interest.

Funding. This research did not receive any specific grant from funding agencies in the public, commercial, or not-for-profit sectors.

\section{References}

Adamson J, Lally J, Gaughran F, Krivoy A, Allen L, and Stubbs B (2017). Correlates of vitamin D in psychotic disorders: A comprehensive systematic review. Psychiatry Research 249, 78-85. doi: 10.1016/j.psychres.2016.12.052

Altieri B, Muscogiuri G, Barrea L, Mathieu C, Vallone CV, Mascitelli L, Bizzaro G, Altieri VM, Tirabassi G, Balercia G, Savastano S, Bizzaro N, Ronchi CL, Colao A, Pontecorvi A, and Della Casa S (2017). Does vitamin D play a role in autoimmune endocrine disorders? A proof of concept. Reviews in Endocrine and Metabolic Disorders 18(3), 335-346. doi: 10. 1007/s11154-016-9405-9

Batalla A, Homberg JR, Lipina TV, Sescousse G, Luijten M, Ivanova SA, Schellekens AFA, and Loonen AJM (2017). The role of the habenula in the transition from reward to misery in substance use and mood disorders. Neuroscience \& Biobehavioral Reviews 80, 276-285. doi: 10.1016/j.neubiorev. 2017.03.019

Blaney GP, Albert PJ, and Proal AD (2009). Vitamin D metabolites as clinical markers in autoimmune and chronic disease. Annals of the New York Academy of Sciences 1173, 384-390. doi: 10.1111/j.1749-6632.2009.04875.x

Brot C, Jørgensen NR, and Sørensen OH (1999). The influence of smoking on vitamin D status and calcium metabolism. European Journal of Clinical Nutrition 53(12), 920-926. doi: 10.1038/sj.ejcn.1600870

Carnicella S and Ron D (2009). GDNF-A potential target to treat addiction. Pharmacology \& Therapeutics 122(1), 9-18. doi: 10.1016/j.pharmthera. 2008.12.001

Cass WA, Smith MP, and Peters LE (2006). Calcitriol protects against the dopamine- and serotonin-depleting effects of neurotoxic doses of methamphetamine. Annals of the New York Academy of Sciences 1074, 261-271. doi: 10. 1196/annals.1369.023

Chow EC, Durk MR, Cummins CL, and Pang KS (2011).1Alpha,25-dihydroxyvitamin D3 up-regulates P-glycoprotein via the vitamin D receptor and not farnesoid $\mathrm{X}$ receptor in both $\mathrm{fxr}(-/-)$ and $\mathrm{fxr}(+/+)$ mice and increased renal and brain efflux of digoxin in mice in vivo. Journal of Pharmacology and Experimental Therapeutics 337(3), 846-859. doi: 10.1124/jpet.111.179101

Cieślińska A, Kostyra E, Fiedorowicz E, Snarska J, Kordulewska N, Kiper K and Savelkoul HFJ (2018). Single nucleotide polymorphisms in the vitamin D receptor gene (VDR) may have an impact on acute pancreatitis (AP) development: A prospective study in populations of AP patients and alcoholabuse controls. International Journal of Molecular Sciences 19(7), 1919. doi: 10.3390/ijms19071919

Cui X, Pelekanos M, Burne TH, McGrath JJ, and Eyles DW (2010). Maternal vitamin $\mathrm{D}$ deficiency alters the expression of genes involved in dopamine specification in the developing rat mesencephalon. Neuroscience Letters 486(3), 220-223. doi: 10.1016/j.neulet.2010.09.057

Drocourt L, Ourlin JC, Pascussi JM, Maurel P, and Vilarem MJ (2002). Expression of CYP3A4, CYP2B6, and CYP2C9 is regulated by the vitamin $\mathrm{D}$ receptor pathway in primary human hepatocytes. Journal of Biological Chemistry 277(28), 25125-25132. doi: 10.1074/jbc.M201323200

Ehlis AC, Reif A, Herrmann MJ, Lesch KP, and Fallgatter AJ (2007). Impact of catechol-O-methyltransferase on prefrontal brain functioning in schizophrenia spectrum disorders. Neuropsychopharmacology 32(1), 162-170. doi: 10.1038/sj.npp.1301151

Ekwaru JP, Zwicker JD, Holick MF, Giovannucci E, and Veugelers PJ (2014). The importance of body weight for the dose response relationship of oral vitamin D supplementation and serum 25-hydroxyvitamin D in healthy volunteers. PLoS One 9(11), 111265. doi: 10.1371/journal.pone.0111265

Eserian JK (2013). Vitamin D as an effective treatment approach for drug abuse and addiction. Journal of Medical Hypotheses and Ideas 7(2), 35-39. doi: 10. 1016/j.jmhi.2013.02.001
Garcion E, Sindji L, Montero-Menei C, Andre C, Brachet P, and Darcy F (1998). Expression of inducible nitric oxide synthase during rat brain inflammation: Regulation by 1,25-dihydroxyvitamin D3. Glia 22(3), 282-294.

Garcion E, Sindji L, Leblondel G, Brachet P, and Darcy F (1999). 1,25dihydroxyvitamin D3 regulates the synthesis of gamma-glutamyl transpeptidase and glutathione levels in rat primary astrocytes. Journal of Neurochemistry 73(2), 859-866. doi: 10.1046/j.1471-4159.1999.0730859.x

Garland CF, Kim JJ, Mohr SB, Gorham ED, Grant WB, Giovannucci EL, Baggerly L, Hofflich H, Ramsdell JW, Zeng K, and Heaney RP (2014). Meta-analysis of all-cause mortality according to serum 25-hydroxyvitamin D. American Journal of Public Health 104(8), e43-e50. doi: 10.2105/AJPH. 2014.302034

Ghaderi A, Banafshe HR, Motmaen M, Rasouli-Azad M, Bahmani F, and Asemi Z (2017). Clinical trial of the effects of vitamin D supplementation on psychological symptoms and metabolic profiles in maintenance methadone treatment patients. Progress in Neuro-Psychopharmacology \& Biological Psychiatry 79(Pt B), 84-89. doi: 10.1016/j.pnpbp.2017.06.016

Ghaderi A, Rasouli-Azad M, Farhadi MH, Mirhosseini N, Motmaen M, Pishyareh E, Omidi A, and Asemi Z (2020). Exploring the effects of vitamin D supplementation on cognitive functions and mental health status in subjects under methadone maintenance treatment. Journal of Addictive Medicine 14(1), 18-25. doi: 10.1097/ADM.0000000000000550

Holick MF (2002). Vitamin D: The underappreciated D-lightful hormone that is important for skeletal and cellular health. Current Opinion in Endocrinology \& Diabetes 9(1), 87-98.

Ibi M, Sawada H, Nakanishi M, Kume T, Katsuki H, Kaneko S, Shimohama S, and Akaike A (2001). Protective effects of 1 alpha,25-(OH)(2)D(3) against the neurotoxicity of glutamate and reactive oxygen species in mesencephalic culture. Neuropharmacology 40(6), 761-771. doi: 10.1016/s0028-3908(01) 00009-0

Kesby JP, Cui X, O'Loan J, McGrath J, Burne TH, and Eyles DW (2010). Developmental vitamin D deficiency alters dopamine-mediated behaviors and dopamine transporter function in adult female rats. Psychopharmacology (Berlin) 208(1), 159-168. doi: 10.1007/s00213-0091717-y

Kongsbak M, Levring TB, Geisler C, and von Essen MR (2013). The vitamin d receptor and $\mathrm{T}$ cell function. Frontiers in Immunology 4, 148. doi: 10.3389/ fimmu.2013.00148

Koob GF and Volkow ND (2010). Neurocircuitry of addiction. Neuropsychopharmacology 35(1), 217-238. doi: 10.1038/npp.2009.110

Loonen AJM and Ivanova SA (2016). Circuits regulating pleasure and happiness in major depression. Medical Hypotheses 87, 14-21. doi: 10.1016/j. mehy.2015.12.013

Loonen AJM and Ivanova SA (2018). Circuits regulating pleasure and happiness: evolution and role in mental disorders. Acta Neuropsychiatrica 30(1), 29-42. doi: 10.1017/neu.2017.8

Loonen AJM, Schellekens AFA, and Ivanova SA (2016). Circuits regulating pleasure and happiness: A focus on addiction, beyond the ventral striatum. In Meil WM and Ruby CL (eds), Recent Advances in Drug Addiction Research and Clinical Applications. Rijeka, Kroatia: Intech, pp. 1-20. doi: $10.5772 / 62707$

Martens PJ, Gysemans C, Verstuyf A, and Mathieu AC (2020). Vitamin D's effect on immune function. Nutrients 12(5), E1248. doi: 10.3390/ nu12051248

Mukhtar M, Sheikh N, Suqaina SK, Batool A, Fatima N, Mehmood R, and Nazir S (2019). Vitamin D receptor gene polymorphism: An important predictor of arthritis development. BioMed Research International 2019, 8326246. doi: 10.1155/2019/8326246

Newton DA, Baatz JE, Kindy MS, Gattoni-Celli S, Shary JR, Hollis BW, and Wagner CL (2019). Vitamin D binding protein polymorphisms significantly impact vitamin D status in children. Pediatric Research 86(5), 662-669. doi: 10.1038/s41390-019-0322-y

Okereke OI, Reynolds CF III, Mischoulon D, Chang G, Vyas CM, Cook NR, Weinberg A, Bubes V, Copeland T, Friedenberg G, Lee IM, Buring JE, and Manson JE 2020). Effect of long-term vitamin D3 supplementation vs placebo on risk of depression or clinically relevant depressive symptoms and on change in mood scores: A randomized clinical trial. JAMA 324(5), 471-480. doi: 10.1001/jama.2020.10224 
Olmos-Ortiz A, Avila E, Durand-Carbajal M, and Diaz L (2015). Regulation of calcitriol biosynthesis and activity: Focus on gestational vitamin D deficiency and adverse pregnancy outcomes. Nutrients 7(1), 443-480. doi: 10. 3390/nu7010443

Pertile RA, Cui X, and Eyles DW (2016). Vitamin D signaling and the differentiation of developing dopamine systems. Neuroscience 333, 193-203. doi: 10.1016/j.neuroscience.2016.07.020

Pike JW and Meyer MB (2010). The vitamin D receptor: New paradigms for the regulation of gene expression by 1,25-dihydroxyvitamin D(3). Endocrinology and Metabolism Clinics of North America 39(2), 255-269. doi: 10.1016/j.ecl. 2010.02.007

Pludowski P, Holick MF, Grant WB, Konstantynowicz J, Mascarenhas MR, Haq A, Povoroznyuk V, Balatska N, Barbosa AP, Karonova T, Rudenka E, Misiorowski W, Zakharova I, Rudenka A, Łukaszkiewicz J, MarcinowskaSuchowierska E, Laszcz N, Abramowicz P, Bhattoa HP, and Wimalawansa SJ (2018). Vitamin D supplementation guidelines. The Journal of Steroid Biochemistry and Molecular Biology 175, 125-135. doi: 10.1016/j.jsbmb. 2017.01.021

Prosser DE and Jones G (2004). Enzymes involved in the activation and inactivation of vitamin D. Trends in Biochemical Sciences 29(12), 664-673. doi: 10.1016/j.tibs.2004.10.005

Puchacz E, Stumpf WE, Stachowiak EK, and Stachowiak MK (1996). Vitamin $\mathrm{D}$ increases expression of the tyrosine hydroxylase gene in adrenal medullary cells. Molecular Brain Research 36(1), 193-196. doi: 10.1016/0169-328x(95) 00314-i

Rapuri PB, Gallagher JC, and Nawaz Z (2007). Caffeine decreases vitamin D receptor protein expression and 1,25(OH)2D3 stimulated alkaline phosphatase activity in human osteoblast cells. The Journal of Steroid Biochemistry and Molecular Biology 103(3-5), 368-371. doi: 10.1016/j. jsbmb.2006.12.037

Schacht JP (2016). COMT val158met moderation of dopaminergic drug effects on cognitive function: A critical review. Pharmacogenomics Journal 16(5), 430-438. doi: 10.1038/tpj.2016.43

Shah AB, DiMartino SJ, Trujillo G, and Kew RR (2006). Selective inhibition of the $\mathrm{C} 5 \mathrm{a}$ chemotactic cofactor function of the vitamin $\mathrm{D}$ binding protein by 1,25(OH)2 vitamin D3. Molecular Immunology 43(8), 1109-1115. doi: 10. 1016/j.molimm.2005.07.023
Sibley DR, Hazelwood LA, and Amara SG (2018). 5-hydroxytryptamine (serotonin) and dopamine. In Brunton LL, Hilal-Dandan R and Knollmann BC (Eds) Goodman \& Gilman's the Pharmacological Basis of Therapeutics, 13th Edn., pp. 225-242. New York, NY, USA: McGraw Hill Medical.

Souberbielle JC, Cavalier E, Delanaye P, Massart C, Brailly-Tabard S, Cormier C, Borderie D, Benachi A, and Chanson P (2015). Serum calcitriol concentrations measured with a new direct automated assay in a large population of adult healthy subjects and in various clinical situations. Clinica Chimica Acta 451(Pt B), 149-153. doi: 10.1016/j.cca.2015.09.021

Tardelli VS, Lago MPPD, Silveira DXD, and Fidalgo TM (2017). Vitamin D and alcohol: A review of the current literature. Psychiatry Research 248, 83-86. doi: 10.1016/j.psychres.2016.10.051

Taylor S (2018). Association between COMT Val158Met and psychiatric disorders: A comprehensive meta-analysis. American Journal of Medical Genetics Part B: Neuropsychiatric Genetics 177(2), 199-210. doi: 10.1002/ ajmg.b.32556

Tekes K, Gyenge M, Folyovich A, and Csaba G (2009a). Influence of neonatal vitamin A or vitamin $\mathrm{D}$ treatment on the concentration of biogenic amines and their metabolites in the adult rat brain. Hormone and Metabolic Research 41(4), 277-280. doi: 10.1055/s-0028-1103287

Tekes K, Gyenge M, Hantos M, and Csaba G (2009b). Transgenerational hormonal imprinting caused by vitamin $\mathrm{A}$ and vitamin $\mathrm{D}$ treatment of newborn rats. alterations in the biogenic amine contents of the adult brain. Brain \& Development 31(9), 666-670. doi: 10.1016/j.braindev.2008.10.007

Tutor JC (2019). Vitamin D supplementation in multiple sclerosis - can be done something more? Medical Hypotheses 129, 109256. doi: 10.1016/j.mehy. 2019.109256

Webb AR, Kline L, and Holick MF (1988). Influence of season and latitude on the cutaneous synthesis of vitamin D3: Exposure to winter sunlight in boston and edmonton will not promote vitamin D3 synthesis in human skin. The Journal of Clinical Endocrinology and Metabolism 67(2), 373-378. doi: 10. 1210/jcem-67-2-373

Wrzosek M, Jakubczyk A, Wrzosek M, Kaleta B, Łukaszkiewicz J, Matsumoto H, Brower K, Nowicka G, and Wojnar M (2014). Association between Fok I vitamin D receptor gene (VDR) polymorphism and impulsivity in alcohol-dependent patients. Molecular Biology Reports 41(11), 7223-7228. doi: 10.1007/s11033-014-3607-6 